\title{
SYAIR LAGU PERMAINAN ANAK TRADISIONAL SEBAGAI LANDAS TUMPU KEMAMPUAN BERBAHASA DI PAUD
}

\author{
Indah Nurmahanani ${ }^{1}$
}

\begin{abstract}
ABSTRAK
Syair lagu anak-anak dalam permainan tradisional bukanlah syair itu semata melainkan yang disiratkannya adalah makna, hakikat dan fungsi syair lagu itu sendiri. Melalui daya metalingual dan bernalar secara metakognisi anak-anak usia dini dapat diajak bertualang dari alam pikiran realita sampai ke alam metafisik. Anak dipacu untuk memilih, memilah serta menyusun pengalaman dan pengetahuannya dalam menanggapi suratan syair lagu dalam permainan tradisional. Itu sebabnya syair lagu anak-anak dalam permainan tradisional dijadikan sebagai landas tumpu kegiatan berbahasa siswa dalam meningkatkan kemampuan berbahasa Indonesia di Pendidikan Anak Usia Dini (PAUD). Penggunaan syair lagu sebagai landas tumpu kemampuan berbahasa Indonesia di PAUD merupakan upaya pembelajaran dengan memberdayakan potensi siswa secara kontekstual dan integratif.
\end{abstract}

Kata kunci: syair lagu, permainan anak tradisional, kemampuan berbahasa Indonesia, PAUD

\section{A. PENDAHULUAN}

Syair lagu permainan tradisional di atas tidak asing bagi anak-anak. Melalui syair lagu itu, anak diajak bertualang dari alam pikiran nyata ke alam metafisik. Melalui daya metalingual dan bernalar secara metakognisi anak dapat dipacu memilih, memilah serta menyusun pengalaman untuk bertutur: apa, mengapa, siapa, kapan, dimana, bagaimana, suratan wacana syair lagu merupakan alam nyata anak, pesannya jauh di alam metafisik yang diharapkan bisa dipahami. Salah satu syair lagu tersebut adalah sebagai berikut.

Syair Lagu: Oray-orayan luar leor mapay sawah

Tong ka sawah - tong ka sawah

Parena keur sedeng beukah

Oray-orayan luar leor mapay kebon

Tong ka kebon - tong ka kebon

Aya barudak keur ngangon

Mending ge teuleum, di leuwi loba nu mandi

Saha nu mandi - saha nu mandi

Anu mandina pandeuri, kok...kok...

Farjcon dan Stewig (1980) mengemukakan syair bukanlah sekuntum mawar melainkan hanya aromanya; bukan lautan melainkan debur gemuruh suara lautnya. Pernyataan menguatkan anggapan yang dikemukakan syair lagu bukan syair itu

1 Dosen PGSD UPI Kampus Purwakarta 
semata, tapi syair yang dapat dijelaskan. Hal ini sesuai dengan pendapat Perrine dalam Stewig (1980), ragam bahasa yang bertutur lebih banyak dan mengkomunikasikan pesan dengan lebih kuat, mendalam dan lebih luas maknanya dari bahasa biasa. Itu sebabnya syair lagu dapat mengungkapkan distilasi pengalaman, emosi, dan pikiran jauh di luar yang disuratkan medium bahasa. Syair lagu dalam permainan anak memiliki ketidakterbatasan ruang dan waktu. Melalui syair lagu dalam permainan anak tradisional anak dapat diajak mengembarakan distilasi pengalaman, emosi, dan pikiran dari alam nyata sampai ke alam metafisik dengan penjalinan daya metalingual dan berpikir metakognisi.

Bermain merupakan cara belajar anak usia dini. Melalui bermain, anak bereksplorasi untuk mengenal lingkungan sekitar, menemukan, memanfaatkan objek-objek yang dekat dengan anak dan kesimpulan mengenai benda di sekitarnya. Ketika bermain anak membangun pengertian yang berkaitan dengan pengalamannya (Depdiknas, 20007: 10). Salah satu permainan tradisional yang digunakan oleh anak-anak di daerah Sunda adalah Oray-orayan. Permainan tradisional daerah Sunda ini terdapat syair lagunya dan anak-anak yang bermain menyanyikan lagu tersebut bersama-sama.

Berdasarkan hal tersebut, maka permasalahannya adalah Bagaimanakah penggunaan syair lagu dalam permainan anak tradisional sebagai landas tumpu kemampuan berbahasa Indonesia di PAUD (Pendidikan Anak Usia Dini)?

\section{B. KEMAMPUAN BERBAHASA INDONESIA DI PAUD}

Istilah kemampuan berdenotasi dengan kompetensi yaitu karakteristik yang ditampilkan oleh seseorang melalui cara berperilaku atau berpikir mengenai berbagai hal dan bertahan dalam waktu yang relatif lama. (Hamzah, Uno,2009: 78). Secara konseptual kemampuan merupakan karakteristik umum yang berkaitan dengan pengetahuan dan keterampilan yang dimiliki seseorang yang diwujudkan melalui tindakan dan mengarah pada peningkatan kinerja.Jadi kemampuan mengacu pada kualitas dalam melaksanakan suatu kegiatan yang dipengaruhi oleh keterampilan dan pengetahuan. Kemampuan dapat diukur melalui atau prestasi hasil belajr yang optimal (Rusman, 2011 :95).

Menurut Semiawan, kemampuan adalah daya untuk melakukan sesuatu tindakan sebagai hasil dari pembawaan latihan. Kemampuan merupakan daya yang didapat sejak lahir oleh setiap manusia yang harus diasah (Conny Semiawan, 1987 : 2).

Salah satu kemampuan yang dimiliki anak-anak adalah berkomunikasi dengan bahasa lisan dan tulisan. Kemampuan berbahasa ini meliputi membaca, menyimak, berbicara dan menulis. Keempat kemampuan berbahasa ini perlu dikembangkan sejak pendidikan anak usia dini sampai perguruan tinggi.

Sesuai dengan hakikat belajar bahasa adalah belajar berkomunikasi dan pembelajaran Bahasa Indonesia diarahkan untuk meningkatkan kemampuan siswa berkomunikasi dengan bahasa Indonesia baik lisan maupun tulisan (Depdiknas 2003 :1). Tujuan umum pembelajaran Bahasa Indonesia seperti dikemukakan Sabarti Akhadiah, M.K, dkk (Bahasa Indonesia I 1992 :10) adalah untuk mengembangkan 
kemampuan menggunakan bahasa Indonesia sebagai sarana berkomunikasi, sarana berpikir, sarana persatuan, dan sarana kebudayaan.

Prinsip dalam mengorganisir kemampuan berbahasa Indonesia di Pendidikan Anak Usia Dini dikemukakan Oleh Pappas (1995) yaitu : (1)children are active, creative learner, (2) language is used for many social puposes, that areexpressed by many language patterns, and (3) knowledge is organized and constructed by individual learners through social interaction. Dengan demikian orientasi peningkatan kemampuan berbahasa anak usia dini adalah kegiatan memberdayakan potensi anak berkomunikasi dengan bahasa Indonesia secara baik dan benar sesuai denagn tujuan dan konteks interaksi sosialnya. Untuk itu, Syair lagu dalam permainan anak tradisional digunakan sebagai landas tumpu kemampuan berbahasa pada anak usia dini. Sehubungan dengan hal tersebut, maka melalui syair lagu dalam permainan anak, maka anak dapat bereksplorasi untuk mengenal lingkungan sekitar dan berekspresi melalui bahasa berdasarkan syair lagu dalam permainan tersebut.

\section{IMPLEMENTASI SYAIR LAGU PERMAINAN ANAK TRADISIONAL UNTUK MELATIH KEMAMPUAN BERBAHASA DI PAUD}

Pembelajaran Bahasa Indonesia agar efektif Goodman (1986: 2) mengemukakan

"its easy when it's real and natural, its whole sensible interesting and relevant, it belongs to the learner, it's part of real event, it has social utility, it has purpose for the learners, the learner chooses to use it, it's accessible to the learner and the learner has power to use it".

Untuk merancang pembelajaran khususnya di PAUD dengan menggunakan syair lagu anak permainan tradisional sebagai landas tumpu pembelajaran dapat dilakukan kegiatan di bawah ini.

\section{Merumuskan Tema}

Merumuskan tema merupakan langkah-langkah awal merancang kegiatan berbahasa. Tema di arahkan untuk mengembangkan kemampuan berbahasa siswa dan perumusannya disesuaikan dengan hasil belajar atau tujuan pembelajaran.

\section{Merumuskan Tujuan Khusus}

Setelah tema dipilih kemudian tujuan khusus kegiatan berbahasa dirumuskan dan diarahkan kepada pemberdayaan potensi berbahasa siswa secara individual, sehingga melalui interaksi ini siswa dapat mengembangkan kemampuannya.

1) Melalui pengamatan terhadap syair lagu permainan anak tradisional "Orayorayan", siswa dapat menceritakan pengalaman dan pengetahuan tentang binatang "ular" dengan bahasa yang mudah dipahami orang lain.

2) Melalui pengamatan terhadap syair lagu permainan anak tradisional "Orayorayan", siswa dapat menuliskan pengalaman dan pengetahuannya tentang "binatang ular" dengan bahasa yang mudah dipahami orang lain. 
3) Melalui pengamatan terhadap syair lagu permainan anak tradisional "Orayorayan", siswa dapat membacakan tulisan pengalaman dan pengetahuan dengan bahasa yang mudah dipahami orang lain.

\section{Memilih dan Menetapkan Bahan Latihan Kemampuan Berbahasa}

Memilih dan menetapkan syair lagu permainan tradisional bahan kegiatan berbahasa disesuaikan dengan minat, perhatian, dan kemampuan siswa, serta tujuan atau hasil belajar yang ingin dicapai. Syair lagu bahan pembelajaran dipilih pula dari permainan tradisional yang telah dikuasai. Dalam hal ini, setelah siswa menyanyikan beberapa lagu, kemudian dipilih salah satu yang dijadikan bahan latihan untuk kemampuan berbahasa.

\section{Merumuskan Kegiatan untuk Melatih Kemampuan Berbahasa}

Berdasarkan bahan pembelajaran terpilih, kemudian dirumuskan kegiatan pembelajaran yang dapat menciptakan siswa berbahasa bersifat alami dan kontekstual.

Contoh kegiatan pembelajaran bahasa dengan menggunakan strategi mapping dan bahan pembelajaran lagu dalam permainan anak tradisional adalah seperti di bawah ini:

a. Siswa menyanyikan lagu dalam permainan anak tradisional Oray-orayan berulang-ulang, kemudian siswa menyebutkan syair lagu baris demi baris dan guru mencatat pada papan tulis dalam bentuk bagan berikut:

b.

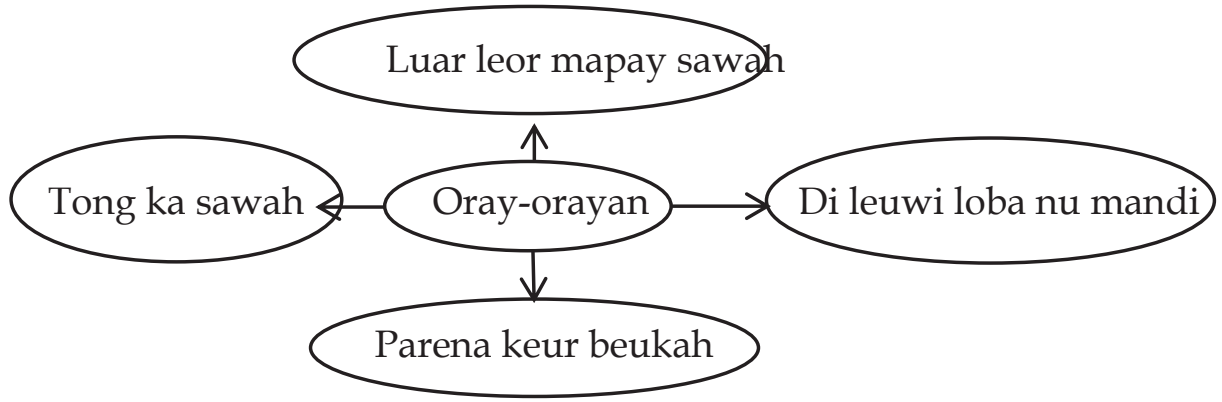

c. Setelah syair lagu dicatat dalam diagram pemetaan semantik (mapping) maka ada lima topik/tema kegiatan berbahasa siswa. Kelima topik/tema itu: (1) oray-orayan, (2) luar leor mapay sawah, (3) di leuwi loba nu mandi, (4) tong ka sawah (jangan ke sawah), (5) parena keur beukah dikembangkan dengan memformulasikan pertanyaan $5 \mathrm{~W}+1 \mathrm{H}$ dan siswa ditugaskan untuk menjawabnya. Contoh bagan pemetaan pengembangan topik/tema adalah seperti di bawah ini.

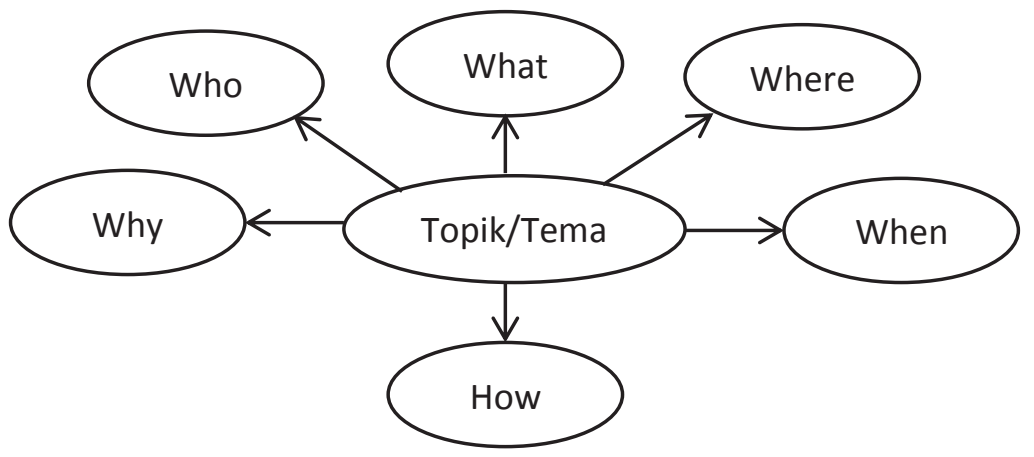


d. Setelah masing-masing topik/tema dijelaskan pengembangannya secara klasikal, siswa dibagi dalam lima kelompok sesuai jumlah topik/tema kemudian merumuskan perihal yang akan disampaikan dalam wacana sesuai topik/tema pilihannya. Wacana siswa harus menjelaskan apa siapa mengapa bagaimana di mana dan kapan dari topik. Hal-hal yang akan diungkapkan pada wacana dapat dirumuskan dahulu dalam bentuk diagram mapping dan ditulis berbentuk kata kunci berupa frase atau kalimat. Contoh diagram adalah seperti dibawah ini:

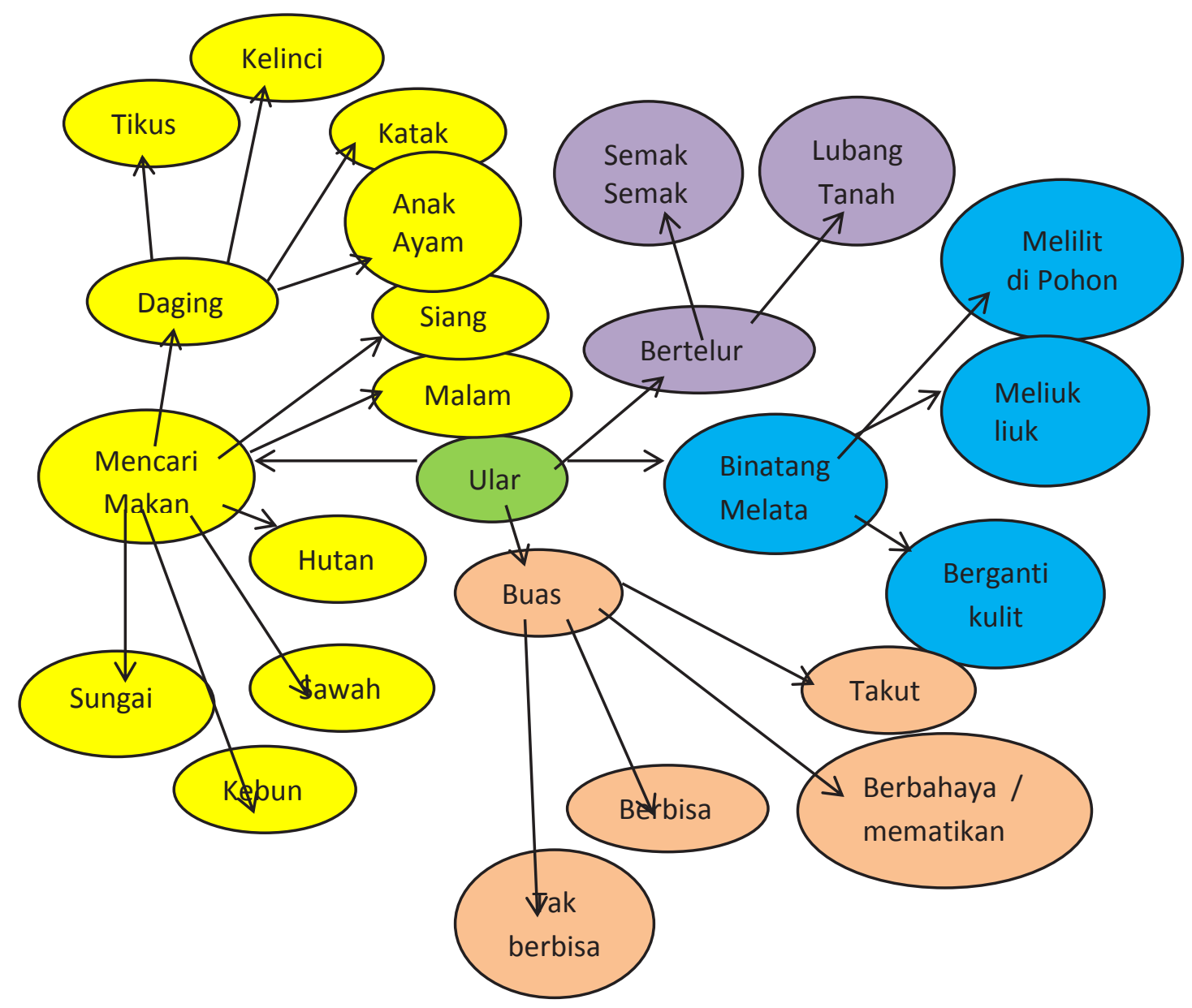

e. Selesai merumuskan dan menyusun wacana, salah seorang siwa wakil dari masing-masing kelompok secara bergiliran menceritakan dan membacakan di depan kelas. Wacana tulis hasil rumusan kelompok diserahkan pula kepada guru untuk dinilai. Pada saat siswa menyampaikan di muka kelas, guru memantau dan membimbing.

f. Sebagai variasi aktivitas siswa dalam pembelajaran, siswa secara individual diberi tugas memilih satu topik untuk kemudian dikembangkan sendiri seperti yang dilakukan dalam kegiatan kelompok setelah seluruh siswa selesai mengerjakan, secara bergiliran siswa ditugaskan menceritakan/membacakan hasil rumusannya di depan kelas dan karya individual siswa diserahkan kepada guru untuk dievaluasi. 
g. Kegiatan akhir pembelajaran, guru memberi komentar hasil karya berbahasa siswa dan memajangkannya pada papan pajangan. Kemudian siswa menilai hasil karya terbaik di kelas dengan menetapkan terbaik 1, 2, 3 dan 4. Hasil karya yang termasuk nominasi terbaik didokumentasikan dalam kumpulan hasil karya-karya terbaik siswa/dijadikan portofolio.

\section{SIMPULAN}

Syair lagu permainan anak tradisional bukan hanya untuk dinyanyikan melainkan mengandung isi dan pesan yang harus dipahami dan dimanfaatkan anakanak usia dini. Suratan syair lagu permainan anak bukanlah syair lagu itu semata melainkan yang disiratkan adalah makna, hakikat dan fungsi syair lagu itu. Melalui daya metalingual dan bernalar secara metakognisi, anak dapat diajak bertualang dari alam pikiran nyata ke alam metafisik. Anak dipacu memilih, memilah serta menyusun pengalaman dan pengetahuan untuk menanggapi. Itu sebabnya syair lagu anak-anak dapat dijadikan sebagai landas tumpu kegiatan berbahasa anak usia dini.

Penggunaan syair lagu permainan tradisional sebagai landas tumpu kemampuan berbahasa anak usia dini pada khususnya merupakan upaya pembelajaran bahasa dengan pemberdayaan potensi anak secara kontekstual dan integratif. Implementasinya diupayakan oleh guru antara lain dengan strategi mapping dan keterpaduan dilakukan tidak terbatas pada satu bidang pengerjaan.

Syair lagu permainan tradisional sebagai landas tumpu kemampuan berbahasa anak usia dini dapat mengefektifkan kemampuan anak bercerita, menulis, dan membaca melalui ketajaman berfikir, bernalar dan kepekaan perasaannya untuk mengungkapkan isi syair lagu.

Penggunaan kosakata, ejaan dan penulisan struktur kalimat dilatih berdasarkan konteks dan pengalaman siswa. Kelemahan yang bisa muncul adalah siswa kurang mampu mengembangkan wacana karena faktor hubungan antara syair lagu permainan tradisional dengan pengalamannya. Siswa yang memiliki pengalaman berhubungan dengan syair lagu cenderung merumuskan dan menyusun wacana lebih maksimal. Sebaliknya siswa yang kurang memperoleh pengalaman, wacana yang dirumuskan dan disusunnya minim.

\section{DAFTAR PUSTAKA}

Akhadiah, M.K. Sabarti, dkk. 1992. Bahasa Indonesia I. Jakarta: Depdikbud

Goodman, Ken. 1986. Whats Whole in Whole Language. Canada: Canadian Catalog in Publication Data.

Pappas, Chirtine, c, dkk. 1995. An Integrated Language Perspective in The Elementary School Theory in to Action. Second Edition. London: Longman Ltd.

Eanes, Robin. 1997. Content Area Literacy Teaching for Today and Tomorrow. Albany Delmer Publishers.

Stewig, John Warren. 1980. Children and Literacy. Chicago: Rand Mc. Nally College Publishing Company.

Semiawan, Conny, 1987. Memupuk Bakat dan Kreativitas Sekolah. Jakarta: Gramedia.

Rusman. 2011. Model-Model Pembelajaran Mengembangkan Profesionalisme Guru. Jakarta: PT. Raja Grafindo Persada. 